\title{
INTRAPERICARDIAL HERNIATION OF THE STOMACH AFTER USE OF THE RIGHT GASTROEPIPLOIC ARTERY FOR CORONARY ARTERY BYPASS GRAFTING
}

Frank Manetta, MD, ${ }^{\mathrm{a}}$ Darroch W. O. Moores, MD, ${ }^{\mathrm{a}, \mathrm{b}}$ Edward V. Bennett, MD, ${ }^{\mathrm{b}}$ and Niloo M. Edwards, MD, Albany, N.Y.

From the Albany Medical Center ${ }^{\mathrm{a}}$ and St. Peter's Hospital, ${ }^{\mathrm{b}}$ Albany, N.Y.

Address for reprints: Darroch W. O. Moores, MD, 319 South Manning Blvd., Suite 301, Albany, NY 12208.

J Thorac Cardiovasc Surg 1998;115:479-80

Copyright (c) 1998 by Mosby, Inc.

$0022-5223 / 98 \$ 5.00+0 \quad \mathbf{1 2 / 5 4 / 8 6 1 9 6}$
The right gastroepiploic artery (GEA) is frequently used as conduit for coronary artery bypass grafting (CABG). Intrathoracic herniation of the stomach has been reported when the GEA pedicle has been routed posterior to the stomach. ${ }^{1-3}$ Recently, a transdiaphragmatic, intrapericardial herniation of the stomach developed in one of our patients after the right GEA pedicle was routed anterior to the stomach. To 


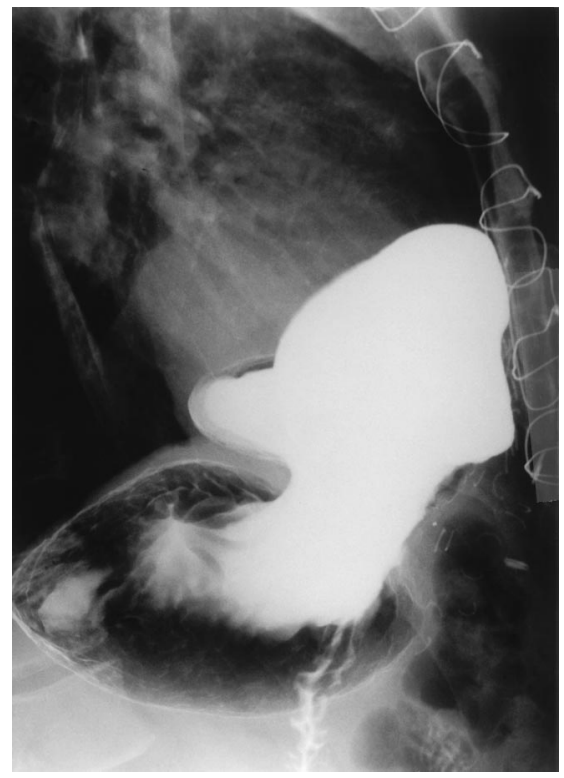

Fig. 1. Lateral upright chest radiograph demonstrates intrapericardial herniation of the stomach.

our knowledge, this is the first report of this complication.

Case report. A 56-year-old man with coronary artery disease had undergone $\mathrm{CABG}$ with autologous vein grafts to the left anterior descending, diagonal, obtuse marginal, and posterior descending coronary arteries in 1984 . He subsequently had recurrent angina and underwent a second CABG in 1994 with the left and right internal thoracic arteries and the GEA to the left anterior descending, circumflex, and distal right coronary arteries, respectively. The GEA pedicle was placed anterior to the stomach.

In April 1997, the patient started to have postprandial epigastric pain followed by nausea and emesis. An upper gastrointestinal radiographic series revealed a intrapericardial gastric hernia (Fig. 1). He subsequently underwent celiac arteriography, which demonstrated a patent right GEA supplying his right coronary artery. The patient underwent exploration through a subxiphoid, upper midline laparotomy. Two thirds of the patient's stomach and omentum were found in the pericardial sac. A plane of dissection was developed between the epicardium and stomach wall. Adhesions continued to the level of the innominate artery. These were lysed, and the stomach and omentum were reduced into the abdominal cavity. There was no hernia sac. The $8 \mathrm{~cm}$ diaphragmatic defect was repaired with a $10 \mathrm{~cm}$ polytetrafluoroethylene surgical membrane patch, ${ }^{*}$ leaving adequate space for the GEA

*Gore-Tex surgical membrane, registered trademark of W.L. Gore \& Associates, Inc., Newark, Del. pedicle. A sternotomy was not performed. The patient was discharged home 4 days after the operation without sequelae.

Discussion. The right GEA was first reported on as a conduit for CABG in $1973 .^{4}$ Subsequent studies have shown it to be a safe and effective conduit. ${ }^{5}$ There is debate regarding the best route for the GEA pedicle. When the pedicle is placed posterior to the stomach and the liver, a greater length of pedicle is available for conduit to complete the coronary anastomosis. The retrogastric route also minimizes the risk of injury during a subsequent laparotomy, whereas the antegastric, antehepatic route has advantages such as ease of handling, ease of visual inspection for bleeding along the pedicle, and theoretic prevention of transdiaphragmatic herniation of the stomach because the GEA pedicle passes through the diaphragm above the left lobe of the liver. Reported complications of using the GEA have been few. Transdiaphragmatic herniations of the stomach and small bowel with the retrogastric route have been reported in both the early and late postoperative periods. ${ }^{1-3}$

The most likely cause of transdiaphragmatic herniation of the stomach in this patient was an overly large window for the GEA pedicle. Risk factors for diaphragmatic hernia, such as chronic cough, obesity, pregnancy, blunt trauma, and ascites, were not present in our patient and can probably be excluded.

We report here the first case of transdiaphragmatic herniation of the stomach after CABG with the GEA placed anterior to the stomach and liver. Although herniation of the abdominal contents is a rare complication, it may be preventable. Techniques such as keeping the GEA pedicle small, minimizing the length of the diaphragmatic incision, placing interrupted sutures perpendicular to the musculotendinous fibers of the diaphragm, ${ }^{2}$ performing a gastropexy, ${ }^{3}$ and reinforcing the diaphragmatic incision with polytetrafluoroethylene mesh may prevent this complication.

\section{REFERENCES}

1. McCaig J, Varghese JC, Rees MR. Case report: Transdiaphragmatic gastric herniation: a rare complication of CABG using the right gastroepiploic artery. Clin Radiol 1996;51: 143-5.

2. Verhofste MA, Tam SK. Diaphragmatic hernia after right gastroepiploic artery coronary artery bypass grafting. Ann Thorac Surg 1995;60:458-9.

3. Pasic M, Carrel T, Von Segesser L, et al. Postoperative diaphragmatic hernia after use of the right gastroepiploic artery for coronary artery bypass grafting. J Thorac Cardiovasc Surg 1994;108:189-91.

4. Edwards WS, Blakely WR, Lewis CE. Techniques of coronary bypass with autologous arteries. J Thorac Cardiovasc Surg 1973;65:272-5.

5. Suma H, Amano A, Horii T, et al. Gastroepiploic artery graft in 400 patients. Eur J Cardiothorac Surg 1996;10:6-10. 